Journal of the Rubber Research Institute of Sri Lanka (2015) 95, 14-23

\title{
Phenotypic diversity of Sri Lankan rubber clones at their immature stage
}

\author{
K K Liyanage* and B W A N Baddewithana* \\ * Genetics and Plant Breeding Dept., Rubber Research Institute of Sri Lanka, Nivitigalakele, \\ Matugama, Sri Lanka
}

\begin{abstract}
Systematic identification of morphological markers useful in the characterization of rubber clones has played a vital role in the crop management system. Although they do not exhibit highly distinct variations, there are certain minor, but more or less stable differences, which can be used for identification. This study was undertaken to estimate morphological diversity present in the Sri Lankan rubber clones at their immature stage and to determine the importance of morphological markers in categorizing different clones into distinct groups. Thirty clones were characterized using 29 standardized morphological descriptors. Principal component analysis (PCA) and Cluster analysis based on first twelve principal components that accounted for $85 \%$ of the total phenotypic variation distinguish 30 clones into six major clusters. Out of 29 descriptors, 27 were informative and contributed significantly to the variation among the clones selected. This study identifies the morphological descriptors that are most important for characterization of rubber clones grown in Sri Lanka.
\end{abstract}

Keywords: characterization, morphological descriptors, principal component analysis, rubber clones

\section{Introduction}

Genetic improvement in Hevea has been described as one of the outstanding success stories in agriculture of the $20^{\text {th }}$ century. The rapid adoption of indigenously bred new clones has contributed substantially to attain higher yield both in the estate as well as in smallholding sectors of the country. Though the handfuls of improved highyielding new clones are available, the genetic base of the existing population is very narrow.

Identification of these clones plays a vital role in the crop management system and research. Knowledge of relatively 
K K Liyanage and B W A N Baddewithana

consistent characters of a clone either singly or in combination will enable to identify different clones recommended for planting. Although clones do not exhibit highly distinct variations, most of them possess certain minor, but more or less stable morphological features, which can be used upon for identification. However, the expression of those characters is the result of the interaction of genotype with an environment in a different magnitude. Hence, it is always desirable to consider those traits that are least influenced.

Use of morphological markers is cost effective when compared to the use of biochemical and molecular markers for preliminary characterization of a large number of accessions (Martinez et. al., 2003). All the clones recommended for planting need to be characterized using a standard set of characters. Morphological classification for rubber is done based on the set of descriptors first suggested by Dijkman (1951), then followed by Jayasekara et.al. (1984), and Mercykutty et. al. (1991). However, the use of minimum but important list of descriptors would help save resources. Therefore, it is necessary to identify highly discriminating descriptors relevant to the clones selected in order to minimize the list of descriptors.
Principal component analysis and cluster analysis are the commonly used multivariate techniques for characterization and genetic diversity analysis of perennial crops such as tea (Wickramaratne, 1981 and Gunasekara et. al., 2001) coconut (Kumaran et.al., 2000).

However, in rubber, numbers of morphological studies were reported in all rubber producing countries (De Silva and Sachuthananthavale, (1961), Paardikooper, (1965), Jayasekara et. al., (1984), Mercykutty et. al., (1991, 2002), Penot and Rasidin, (1994) and Michel and Beningo, (1994)) and all of them were confined to collection of morphological data for identifying the clones. There is no evidence for statistical analysis for characterization of clones based on their morphological descriptors. Therefore, the objective of the present study was to identify key morphological features contributing to the total phenotypic variation among the Sri Lankan rubber clones at their immature stage.

\section{Materials and Methods}

Thirty of the Sri Lankan rubber clones in the 100 series, 200 series and 2000 series were selected (Table 1) (Attanayake, 2001). 
Phenotypic diversity of Sri Lankan rubber clones

Table 1. Recommended clones and their parentages

\begin{tabular}{|c|c|c|}
\hline & Clone & Parentage \\
\hline 01 & RRIC 100 & RRIC $52 \times$ PB 86 \\
\hline 02 & RRIC 102 & RRIC $52 \times$ RRIC 7 \\
\hline 03 & RRIC 121 & PB $28 / 59 \times$ IAN $45 / 873$ \\
\hline 04 & RRIC 130 & IAN 45/710 x RRIC 45 \\
\hline 05 & RRIC 133 & IAN $45 / 710 \times$ RRIC 52 \\
\hline 06 & RRISL 201 & RRIC 103 x HP 8501 \\
\hline 07 & RRISL 203 & RRIC $100 \times$ RRIC 101 \\
\hline 08 & RRISL 205 & $82 \mathrm{HP} \times 82 \mathrm{HP}$ \\
\hline 09 & RRISL 206 & $82 \mathrm{HP}$ x RRIC 101 \\
\hline 10 & RRISL 208 & RRIC 101 x RRIM 600 \\
\hline 11 & RRISL 210 & RRIC $101 \times$ RRIM 600 \\
\hline 12 & RRISL 211 & RRIC 101 x RRIM 600 \\
\hline 13 & RRISL 215 & Illegitimate \\
\hline 14 & RRISL 216 & Illegitimate \\
\hline 15 & RRISL 217 & PB 28/59 x RRIC 121 \\
\hline 16 & RRISL 218 & PB 28/59 x RRIC 121 \\
\hline
\end{tabular}

\begin{tabular}{|c|c|c|}
\hline & Clone & Parentage \\
\hline 17 & RRISL 219 & PB 28/59 x RRIC 102 \\
\hline 18 & RRISL 220 & PB 28/59 x RRIC 121 \\
\hline 19 & RRISL 221 & RRIC 52 x PB 28/59 \\
\hline 20 & RRISL 222 & RRIC $102 \times$ IAN $45 / 710$ \\
\hline 21 & RRISL 223 & PB $28 / 59$ x IAN $45 / 710$ \\
\hline 22 & RRISL 225 & RRIC 102 x PB $28 / 59$ \\
\hline 23 & RRISL 226 & RRIC 102 x PB 28/59 \\
\hline 24 & RRISL 2000 & RRIC $100 \times$ RRIC 101 \\
\hline 25 & RRISL 2001 & RRIC $100 \times$ RRIC 101 \\
\hline 26 & RRISL 2002 & RRIC $100 \times$ RRIC 101 \\
\hline 27 & RRISL 2003 & $82 \mathrm{HP}$ x RRIC 101 \\
\hline 28 & RRISL 2004 & $82 \mathrm{HP} \times \mathrm{PB} 86$ \\
\hline 29 & RRISL 2005 & PB $28 / 59 \times$ IAN $45 / 710$ \\
\hline 30 & RRISL 2006 & PB 28/59 x RRIC 36 \\
\hline
\end{tabular}

The clones raised in the polybags were transplanted into the field with the spacing of $3^{\prime} \times 3^{\prime}$ in a completely randomized block design. Characters were recorded at the plant at 12 to 18 months aged from fifteen plants five each randomly selected from three replicates. Data were collected from the top most nature leaf whorl.

All informative morphological data were selected based on the previous studies carried out by early researchers. As the descriptors used in the study consisted of quantitative and qualitative characters such as;

- Nodes - axillary buds and leaf scars

- Leaf storey - shape, separation and external appetence of leaf storey

- Petiole and petiolule - pulvinus, shape, size, orientation, angle and size of petiole

- Leaves - colour, lusture, texture, shape and size, cross-section and longitudinal section appearance, leaf apex, leaf base, leaf margin and degree of separation

were collated.

Non-parametric data were converted on a scale of numeric data to enable them to be used in statistical analysis. Principal Component Analysis (PCA) was carried 
K K Liyanage and B W A N Baddewithana

out using means of quantitative and modes of qualitative morphological characters. Average linkage cluster analysis was performed subsequently based on the significant number of Principal Components (PC) aiming at grouping of the 30 rubber clones. The analysis was performed using SAS Version 9.2 (Annon, 2008).

\section{Results and Discussion}

Correlation matrices obtained from the PCA of the 29 morphological descriptors shows that Eigenvalues of the first 12 principal components (PCs) were greater than one and they were significantly contributed to the variation existing in the clones studied. Furthermore, those 12 PCs accounted for the $85 \%$ of the total variation (Table 2).

Then the eigenvectors generated by the first 12 PC shows that some of the variables (which are highlighted) are comparatively higher than the other variables (Table 2). Although all the twenty-nine variables have contributed to a certain degree to deciding the position of each of first twelve principal components, it is clearly evident that some of the variables play comparatively significant role in selecting the position of each PCs indicating that they are the main contributors in each component.

When explaining the above patterns of the 29 variables, it was clearly evident that 27 variables have contributed significantly to decided the positioning of the first eleven PCs and ultimately to the variation (Table $3)$. Only two variables were found comparatively less significant. They were the orientation of pulvinus and the nature of veins.

Through the PC analysis, it was able to reduce the number of descriptors (or combinations of descriptors) in the form of principal components. To achieve the main objective of grouping the accessions, cluster analysis was performed based on average linkage on the first twelve principal components. The dendrogram (Fig. 1) indicates that the 30 rubber clones used in this study were grouped into six well-defined clusters at the average distance of 1.0 . 
Table 2. Eigenvectors and eigenvalues of the first twelve principal components of twenty-nine quantitative traits of 30 Sri Lankan rubber clones

\begin{tabular}{|c|c|c|c|c|c|c|c|c|c|c|c|c|}
\hline \multirow[b]{2}{*}{ Characters } & \multicolumn{12}{|c|}{ Eigenvectors } \\
\hline & PC 1 & PC 2 & PC 3 & PC 4 & PC 5 & PC 6 & PC 7 & PC 8 & PC 9 & PC 10 & PC 11 & PC12 \\
\hline 1 & -0.1383 & -0.1875 & -0.2483 & -0.0027 & -0.0945 & -0.2132 & 0.2801 & 0.0120 & 0.4183 & 0.1542 & 0.1855 & -0.0330 \\
\hline 2 & -0.1003 & 0.2320 & -0.1700 & 0.0451 & -0.1039 & 0.2478 & 0.0688 & 0.2613 & 0.2030 & -0.1586 & 0.0703 & -0.4351 \\
\hline 3 & 0.0578 & 0.0706 & -0.4895 & 0.0747 & 0.0961 & 0.1149 & -0.2057 & -0.0403 & -0.0132 & -0.0229 & -0.2346 & 0.2717 \\
\hline 4 & -0.1593 & -0.0768 & 0.2220 & 0.0973 & 0.4359 & 0.1200 & -0.1923 & -0.1258 & -0.0473 & 0.0836 & 0.0583 & -0.1127 \\
\hline 5 & -0.2259 & -0.1829 & 0.0283 & -0.3552 & 0.1279 & 0.0836 & 0.0112 & -0.2205 & 0.0372 & 0.0898 & 0.1219 & -0.0073 \\
\hline 6 & 0.1482 & 0.1799 & 0.0739 & -0.4603 & 0.0414 & -0.2085 & 0.1217 & -0.0514 & -0.0098 & -0.1599 & 0.2341 & -0.0999 \\
\hline 7 & 0.0950 & 0.2420 & -0.2380 & 0.2657 & 0.3297 & 0.1277 & 0.1764 & -0.0680 & 0.1230 & 0.0393 & 0.0823 & -0.0619 \\
\hline 8 & 0.2406 & -0.2095 & 0.1173 & 0.0611 & 0.2992 & -0.1127 & 0.2790 & 0.1880 & 0.0741 & 0.0255 & -0.0611 & 0.0242 \\
\hline 9 & -0.1353 & 0.1162 & 0.3607 & 0.2583 & -0.1918 & 0.1979 & 0.0153 & 0.1357 & 0.2249 & 0.0421 & -0.0934 & -0.0589 \\
\hline 10 & 0.2580 & 0.1217 & 0.1022 & 0.0623 & 0.3672 & 0.0364 & 0.1949 & 0.0752 & 0.2730 & 0.2160 & 0.0049 & 0.1461 \\
\hline 11 & -0.1821 & 0.2611 & -0.0013 & 0.0496 & 0.2185 & -0.0590 & 0.1541 & -0.3611 & -0.2693 & -0.0669 & 0.0935 & 0.2183 \\
\hline 12 & -0.0148 & -0.4186 & 0.0432 & 0.0438 & 0.1892 & -0.1076 & -0.0810 & 0.2006 & 0.1539 & -0.0145 & -0.2297 & 0.0365 \\
\hline 13 & 0.0178 & 0.1724 & 0.1021 & 0.1810 & 0.0844 & -0.3065 & 0.1124 & 0.4047 & -0.3412 & 0.0936 & 0.1443 & 0.1927 \\
\hline 14 & 0.1340 & 0.3411 & 0.0843 & -0.2690 & 0.0677 & -0.0578 & -0.1534 & 0.0662 & 0.2688 & 0.1480 & 0.1457 & 0.0760 \\
\hline 15 & 0.2306 & -0.1851 & 0.2350 & 0.0652 & 0.0962 & 0.2663 & -0.0475 & -0.1664 & 0.1811 & -0.3471 & -0.0465 & 0.1579 \\
\hline 16 & 0.3440 & -0.0264 & 0.2171 & -0.1801 & -0.0639 & 0.1006 & 0.0697 & 0.1896 & 0.0114 & -0.0050 & 0.0950 & -0.0734 \\
\hline 17 & 0.3033 & -0.0416 & -0.1349 & -0.2170 & -0.0804 & -0.0919 & -0.2628 & -0.0775 & -0.0706 & 0.3096 & -0.1793 & -0.2123 \\
\hline 18 & 0.3551 & -0.0705 & -0.0752 & 0.0380 & -0.0757 & 0.1058 & 0.0933 & -0.1514 & -0.1329 & 0.0854 & -0.3155 & -0.2046 \\
\hline 19 & 0.1627 & 0.0444 & 0.1113 & 0.3228 & 0.0856 & -0.3398 & -0.3482 & -0.1187 & -0.0559 & 0.0031 & -0.0134 & -0.1904 \\
\hline 20 & 0.2208 & -0.0827 & 0.1749 & 0.1380 & -0.3754 & -0.1042 & 0.1884 & -0.1120 & -0.1856 & 0.1827 & 0.1076 & 0.1684 \\
\hline 21 & 0.1915 & 0.0719 & -0.0945 & 0.2804 & -0.2527 & 0.3383 & 0.0403 & -0.1024 & 0.0177 & 0.1273 & 0.2901 & 0.1566 \\
\hline 22 & -0.1782 & 0.2656 & 0.3979 & -0.0717 & -0.0184 & 0.1744 & -0.0324 & 0.0259 & -0.0962 & 0.0054 & -0.2751 & -0.0962 \\
\hline 23 & 0.2076 & 0.1184 & -0.0513 & -0.1438 & -0.0612 & -0.0082 & -0.1084 & 0.1236 & 0.0770 & -0.5501 & -0.0920 & 0.3779 \\
\hline 24 & -0.1324 & 0.0792 & 0.0521 & -0.1375 & -0.0909 & -0.0023 & 0.4500 & -0.1578 & 0.0622 & 0.1514 & -0.5142 & 0.1972 \\
\hline
\end{tabular}




\begin{tabular}{|c|c|c|c|c|c|c|c|c|c|c|c|c|c|}
\hline \multirow{2}{*}{\multicolumn{2}{|c|}{ Characters }} & \multicolumn{12}{|c|}{ Eigenvectors } \\
\hline & & PC 1 & PC 2 & PC 3 & PC 4 & PC 5 & PC 6 & PC 7 & PC 8 & PC 9 & PC 10 & PC 11 & PC12 \\
\hline & 25 & -0.0582 & -0.1114 & 0.1982 & 0.1019 & -0.1694 & -0.1718 & -0.1838 & -0.3344 & 0.3557 & 0.0208 & 0.1835 & 0.1960 \\
\hline & 26 & 0.1341 & -0.1647 & 0.0247 & -0.1825 & 0.1287 & 0.4479 & 0.0054 & -0.0527 & -0.2188 & 0.2094 & 0.2426 & 0.0583 \\
\hline & 27 & -0.0858 & -0.3379 & -0.0294 & 0.0595 & -0.0032 & 0.0468 & 0.2363 & 0.0681 & -0.2454 & -0.3234 & 0.1694 & -0.1360 \\
\hline & 28 & -0.2065 & -0.1158 & -0.0295 & -0.1048 & -0.0462 & 0.1688 & -0.2456 & 0.4121 & -0.0430 & 0.2756 & 0.0248 & 0.3657 \\
\hline & 29 & 0.0000 & 0.0000 & 0.0000 & 0.0000 & 0.0000 & 0.0000 & 0.0000 & 0.0000 & 0.0000 & 0.0000 & 0.0000 & 0.0000 \\
\hline Eigen value & & 3.958 & 3.097 & 2.411 & 2.201 & 2.163 & 1.739 & 1.681 & 1.628 & 1.438 & 1.308 & 1.142 & 1.037 \\
\hline $\begin{array}{l}\% \text { of total } \\
\text { variance }\end{array}$ & & 14.1 & 11.0 & 8.6 & 7.8 & 7.7 & 6.2 & 6.0 & 5.8 & 5.1 & 4.6 & 4.0 & 3.7 \\
\hline $\begin{array}{l}\% \text { cumulativ } \\
\text { variance }\end{array}$ & & 14.1 & 25.2 & 33.8 & 41.6 & 49.4 & 55.6 & 61.6 & 67.4 & 72.5 & 77.2 & 81.3 & 85.0 \\
\hline
\end{tabular}

1 - Axillary bud,

2 - Leaf scar

3 - Shape of leaf scar

4 - Shape of leaf storey

5 -Separation of leaf storey

6 - Ext. appearance of leaf storey

7 - Size and width of leaf storey

8 - Pulvinus
9 - Petiole shape

10 - Petiole size

11 - Petiole orientation

12 - Petiolue orientation

13 - Petiolule angle

14 - Petiolule size

15 - Petiolule junction appearance

16 - Leaflet colour
17 - Leaflet luster

18 - Leaflet texture

19 - Leaflet shape

20 - Leaf area

21 - Leaflet thickness

22 - Leaf margin

23 - Degree of leaflet separation

24 - Cross-sectional appearance
25 - Longitudinal sectional appearance

26 - Shape of leaf apex

27 - Shape of leaf base

28 - Colour of veins

29 - Nature of veins 
Table 3. Main contributor descriptors for each principal component (PC)

\begin{tabular}{ll}
\hline PC & Main descriptors \\
\hline 1 & Leaflet colour, Leaflet luster, Leaflet texture \\
2 & Petiolue orientation, Petiolule size, Shape of leaf base \\
3 & Shape of leaf scar, Petiole shape, Leaf margin \\
4 & Separation of leaf storey, External appearance of leaf storey \\
5 & Shape of leaf storey, Size and width of leaf storey, Petiole size, Leaf area \\
6 & Petiolule angle, Leaflet shape, Leaflet thickness, Shape of leaf apex \\
7 & Leaflet shape, Cross-sectional appearance \\
8 & Petiole orientation, Petiolule angle, Longitudinal sectional appearance, Colour of veins \\
9 & Axillary bud, Longitudinal sectional appearance \\
10 & Petiolule junction appearance, Leaflet luster, Degree of leaflet separation, Shape of leaf base \\
11 & Cross-sectional appearance, Leaflet shape \\
12 & Leaf scar, Degree of leaflet separation, Colour of veins \\
\hline
\end{tabular}

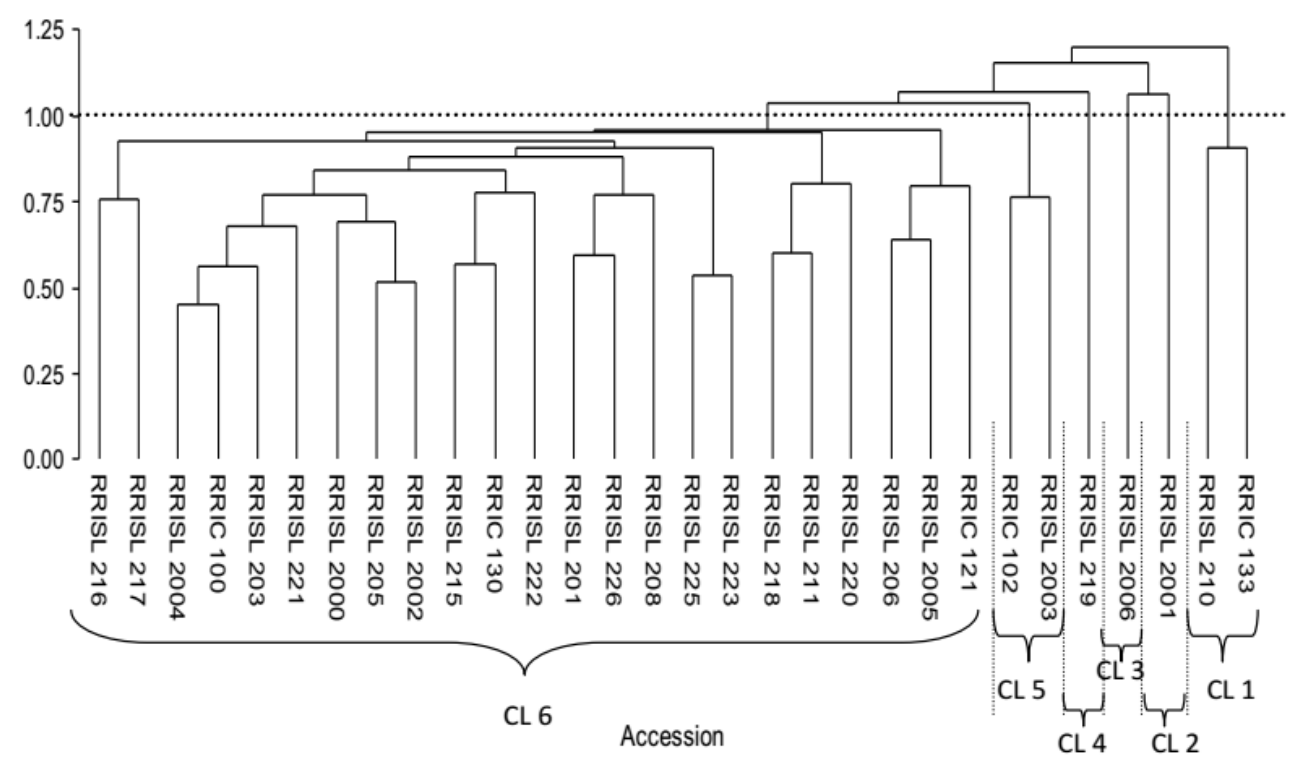

Fig. 1. Dendrogram for 30 rubber clones under studied based on average linkage cluster analysis using 29 morphological descriptors (CL 1 to CL 6 is the different clusters at average distance of 1.0) 
K K Liyanage and B W A N Baddewithana

Cluster 1 consists of two clones, RRIC 133 and RRISL 210. They possess longer petiolule, dark colour leaflets, glossy luster and smooth texture than other clones that help in the form of a separate cluster.

In cluster 2, consist only one clone RRISL 2001 and it was clearly separated from others because it had a unique morphological feature like circular shape leaf scars and it process some other very important features like broad elliptical shape leaflets, smooth leaf margin, arched shape petiole, apiculate leaf apex and it had leaflets with "S" shape in the longitudinal sectional appearance. Though these characters are not unique to the clone RRISL 2001, by a combination of these characters together it is easy to separate out this clone from others.

The cluster 3 consists only one clone RRISL 2006, and it possessed features of conical shaped leaf story, light green colour leaflets and aristate type leaf apex. The combination of these characters together helped to identify clone RRISL 2006 separately from others.

Cluster 4 includes only one clone RRISL 219 which differs significantly from the upward orientation of petiloule, broad elliptical shape leaf storey, straight appearance of the petiolule junction and touching habit of the leaflet in leaflet separation character. Although those characters are not common to RRISL 219 , combinations of them together helped to identify this clone easily.

Cluster 5 includes two clones RRISL 2003 and RRIC 102, and both have common features of conical shape leaf storey, broad elliptical shape leaflets and thin (thickness) leaflets that help to form a separate cluster. Within the cluster, those two can separated from their shape of the petiole, degree of leaflet separation, the shape of the leaf apex and leaf base.

The remaining 23 clones formed a major cluster (Cluster 6) which shows more resemblances in their morphology. This is because that most of the clones possess similar traits due to lower genetic diversity as they were derived from common ancestors.

The present analysis of morphological characters provides the basis for broad classification of rubber clones and PCA identifies the variables contributing to most of phenotypic diversity while clustering helps in grouping of clones based on their degree of relationship to each other based on their common morphological features.

\section{Conclusions}

This study classified the 30 rubber clones recommended to grow in Sri Lanka into well-defined phenotypic groups. Principal component analysis (PCA) using 29 morphological descriptors and cluster analysis based on first 12 principal components (PCs) group all 30 clones 
into six major clusters. Among all 29 descriptors measured, 27 descriptors highly contributed to the phenotypic diversity of the clones. Although clones do not exhibit highly distinct variations, most of them possess certain minor, but more or less stable morphological features, which can be used upon for identification. Analysis of morphological characters provides the basis for broad classification of rubber clones, and PCA identifies the variables contributing to most of phenotypic diversity of the clones.

\section{References}

Anon (2008). Statistical analysis system (SAS) for Windows versions 9.2. SAS Institute, USA.

Anon (2010). Annual Report of the Central Bank.

Attanayake, D P T S G (2001). Clones for commercial planting in Sri Lanka. Handbook of Rubber. Rubber Research Institute of Sri Lanka, Vol. 1, pp. 46-53.

De Silva, C A and Satchuthananthavale, R (1961). History and description of promising RRIC clones. Journal of Rubber Research Institute of Ceylon 37(2), 112128.

Dijkman, M J (1951). Hevea Thirty years of research in far east. University of Miami Press, Florida, pp.155-177.

Gunasekara, M T K, Kottawa Arachchige, J $\mathrm{D}$, Mudalige, $\mathrm{A} \mathrm{K}$ and Peiris, $\mathrm{T} \mathrm{U} \mathrm{S}$ (2001). Morphological diversity of Tea (Camellia sinensis L) genotypes in Sri Lanka, pp 83. In: Proceedings of the $57^{\text {th }}$
Annual Session of Sri Lanka Association of Advancement of Sciences (SLAAS), Part I.

Jayasekara, N E M, Fernado, D M and Karunasekara, K B A (1984), Identification of clones. A Practical Guide to Rubber Planting and Processing. Rubber Research Institute of Sri Lanka, pp.10-18.

Kumaran, P M, Koshi, P K, Arunachalam, V, Niral, V and Parthasarathy, V A (2000). Biometric clustering of coconut population of three Indian Ocean islands. Recent Advances in Plantation Crop Research, 78-81.

Martinez, L, Masuelli, R and Rodriguez, J (2003). Evaluation of diversity among Argentine grapevine (Vitis vinifera L.) varieties using morphological data and AFLP markers. Journal of Biotechnology 6 (3), 242-250.

Mercykutty, V C, Annamma Varghese, Y, Licy, J and Panikkar, A O N (1991). Juvenile characters and seed morphology of certain modern Hevea clones. Indian Journal of Natural Rubber Research 4 (1), 16-25.

Mercykutty, V C, Jaseph, G H, Saraswathyamma, C K and Meenakumari, T (2002). Identification of Hevea clone: $A$ Manual. Rubber Research Institute of India.

Michel Delabarre, A and Dante Benigno, A (1994). Rubber: A Pictorial Technical Guide for Smallholders, CIRAD-CP, France, pp.153.

Paadekooper, E C (1965). Clones of commercial interest in Malaya. Planting Manual. Rubber Research Institute of Malaysia. pp.135. 
K K Liyanage and B W A N Baddewithana

Penot, E and Rasidin, Aswar (1994). Rubber clone index in Indonesia. Indonesian Rubber Research Institute.

Wicramaratne, M R T (1981). Variation of some leaf characteristics in Tea (Camellia sinensis L) and their use in identification of clones. The Tea Quarterly 50, 183-198.
Address for correspondence: K K Liyanage, Senior Research Officer, Genetics \& Plant Breeding Dept., Rubber Research Institute of Sri Lanka, Nivithigalakele, Matugama, Sri Lanka.

e-mail:1kapila@ymail.com 